\title{
Les récepteurs centraux de la sérotonine
}

\section{Michel Hamon Henri Gozlan}

\section{ADRESSE}

M. Hamon, H. Gozlan. Inserm U. 288, neurobiologic cellulaire et fonctionnelle faculté de médecinc Pitié-Salpêtrière, 91, boulevard de l'Hôpital, 75634 Paris Cedex 13, France.

La sérotonine (5-hydroxytryptamine, 5-HT) est un neurotransmetteur intervenant dans le contrôle de nombreuses fonctions cérébrales : cycles veille/sommeil, thermorégulation, comportement de faim/satiété, comportement sexuel, nociception, etc. De plus, des désordres neuropsychiatriques tels que les dépressions, les démences et l'anxiété sont associés à des anomalies fonctionnelles des neurones sérotoninergiques. Cette diversité de fonctions de la 5-HT est très probablement en rapport avec la multiplicité de ses récepteurs (au moins dix), certains d'entre eux étant couplés à plusieurs systèmes effecteurs. La caractérisation moléculaire, structurale et fonctionnelle, des récepteurs qu'autorise le clonage préalable de leurs gènes devrait permettre de développer de nombreux médicaments d'indications très spécifiques et entraînant un minimum d'effets secondaires.

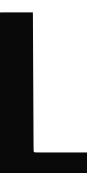

a sérotonine ou 5-hydroxytryptamine (5-HT), initialement identifiée au niveau périphérique (elle est très abondante dans les cellules entérochromaffines dc l'intestin et dans les plaquettes sanguines), a été mise en évidence dans le système nerveux central (SNC) des mammifères il y a une quarantaine d'années. Très vite, la démonstration de l'hétérogénéité de la distribution de la 5-HT au niveau cérébral a conduit à suggérer que cette amine y jouait le rôle de neuromédiateur. Depuis, les recherches ont progressé par bonds, suivant en cela l'avènement de nouvelles techniques biochimiques, anatomiques, électrophysiologiques, etc., ainsi que le développement de nouveaux outils pharmacologiques ou moléculaires. Il est aujourd'hui clairement établi que les neurones qui synthétisent et libèrent la 5-HT (les ncurones sérotoninergiques) participent au contrôle de nombreuses fonctions centra- les telles que lc rythme vcillesommeil, la prise alimentaire, la nociception, la thermorégulation, l'activité sexuelle, etc. De plus, des altérations de la transmission sérotoninergique centrale sont associées à diverses affections psychiatriques et/ou neurologiques, en particulier la dépression et l'anxiété sous leurs différentes formes, les démences (y compris la maladie d'Alzheimer), etc. Cette pluralité d'interventions de la $5-\mathrm{HT}$ au niveau central a conduit à postuler que ce neuromédiateur agissait sur plusieurs types de récepteurs dans les membranes des ccllules cibles des neurones sérotoninergiques. D'ailleurs, dès 1957, Gaddum et Picarelli [1] apportaient les premiers arguments expérimentaux en faveur de l'existence d'au moins deux types de récepteurs pour la 5-HT. Depuis, la situation a considérablement évolué puisque l'application des techniques de la biologie moléculaire a permis le clonage et le séquençage des $\mathrm{ADNc}$ 


\section{RÉFÉRENCES}

1. Gaddum JH, Picarclli ZP. Two kinds of tryptamine receptors. BrJ Pharmacol 1957 ; 12 : 323-8.

2. Hartig PR, Branchek TA, Weinshank RL. A subfamily of 5-HT, receptor gencs. Trends Pharmacol Si 1992 ; 13 : 152-9.

3. Bockacrt J, Fozard JR, Dumuis A, Clarke DE. The 5-HT 4 receptor: a place in the sun. Trends Pharmacol Sci $1992 ; 13$ : 141-5.

4. Miquel MC, Hamon M. 5-HT, receptor subtypes : pharmacological heterogencity. In : Langer SZ, Bruncllo $\mathrm{N}$, Racagni $\mathrm{G}$, Mendlewicz J, cds. Serotonin Receptor Subtypes: Pharmacological Significance and Clinical Implications. Bâlc : Karger, 1992 : 13-30.

5. Julius D, Huang $\mathrm{KN}$, Livelli 'IJ, Axcl R, Jessell TM. The 5- $\mathrm{HT}_{2}$ receptor defines a family of structurally distinct but functionally conserved serotonin receptors. Proc Natl Acad Sci USA 1990 ; 87 : 928-32.

6. Kobilka BK, Friclle $\mathrm{T}$, Collins $\mathrm{S}$, et al. An intronless gene encoding a potential member of the family of receptors coupled to guanine nuclcotide regulatory proteins. Nature $1987 ; 329: 75-9$.

7. Fargin A, Raymond JR, Lohsc MJ, Kobilka BK, Caron MG, Lefkowitz RJ. The genomic clone G-21 which resembles a $\beta$-adrenergic receptor sequence encodes the $5-\mathrm{HT}_{1 \mathrm{~A}}$ receptor. Nature $1988 ; 335$ : 358-60.

8. Albert PR, Zhou QY, Van Tol HHM, Bunzow JR, Civclli O. Cloning, mRNA tissue distribution, and functional expression of the rat 5-HT ${ }_{1 \mathrm{~A}}$ receptor gene. J Biol Chem 1990 ; 265 : 5825-32.

9. Liu YF, Albert PR. Cell-specific signalling of the 5-HT 1 A receptor. J Biol Chem $1991 ; 266: 23689-97$.

10. Miquel MC, Doucet E, Boni C, et al. Central serotonin ${ }_{1 \Lambda}$ receptors : respective distributions of encoding mRNA, receptor protein and binding sites by in situ hybridization histochemistry, radioimmunohistochemistry and autoradiographic mapping in the rat brain. Neurochem Int 1991; 19 : 453-65.

11. Sotelo C, Cholley B, El Mestikawy S, Gozlan H, Hamon M. Direct immunohistochemical evidence of the existence of $5-\mathrm{HT}_{1 \wedge}$ autoreceptors on serotoninergic ncurons in the midbrain raphe nuclei. Eur J Neurosci 1990 ; 2 : 1144-54.

12. Vergé D, Daval G, Marcinkicwicz M, et al. Quantitative autoradiography of multiple 5-HT, receptor subtypes in the brain of control or 5,7-dihydroxytryptaminetreated rats. I Neurosci $1986 ; 6$ : 3474-82. d'une dizaine de récepteurs distincts. Comme pour d'autres neuromédiateurs (acétylcholine, acide $\gamma$-aminobutyrique ou GABA, glutamate), la 5-HT agit sur des récepteurs qui sont couplés à une protéine $\mathrm{G}$, ou bien constituent un canal ionique. Les potentialités thérapeutiques de ligands sélectifs de seulement quelques types de récepteurs de la 5 -HT dont nous disposons aujourd'hui laissent à penser que l'étude approfondie de toutes les classes de récepteurs de ce neuromédiateur débouchera sur la synthèse de nouveaux composés pour de nouvelles indications en clinique.

\section{Les récepteurs couplés aux protéines $G$}

Ils constituent la majorité des récepteurs de la 5-HT que les études pharmacologiques ont permis de classer en types $5-\mathrm{HT}_{1 \mathrm{~A}}, 5-\mathrm{HT}_{1 \mathrm{~B}}, 5-\mathrm{HT}_{1 \mathrm{C}}$, $5-\mathrm{HT}_{1 \mathrm{D}}, 5-\mathrm{HT}_{1 \mathrm{E}}, 5-\mathrm{HT}_{2}$ et $5-\mathrm{HT}_{4}$ (Tableau I). En fait, le clonage a montré que cette classification ne rendait pas compte de tous les types de récepteurs appartenant à cette famille étant donné que, par exemple, des sous-types $5-\mathrm{HT}_{1 \mathrm{D} \alpha}$ et $5-\mathrm{HT}_{1 \mathrm{D} \beta}$ ont été isolés récemment [2]. Cependant, des ligands sélectifs n'existent pas encore pour tous ces récepteurs (Tableau I), et leurs fonctions respectives dans les effets centraux de la 5-HT sont souvent assez mal connues.

Les différences classes de récepteurs 5-HT, sont caractérisées par une haute affinité pour la 5-HT (Kd nanomolaire), par opposition aux récepteurs $5-\mathrm{HT}_{2}$ et $5-\mathrm{HT}_{4}$ dont l'affinité pour le ligand endogène est environ mille fois plus faible. Outre leurs propriétés pharmacologiques respectives (Tableau I), les mécanismes de transduction associés à ces deux derniers récepteurs permettent de les différencier aisément. Le récepteur 5- $\mathrm{HT}_{2}$ est couplé, par l'intermédiaire d'une protéine $\mathrm{G}$, à la phospholipase $\mathrm{C}$, alors que le récepteur $5-\mathrm{HT}_{4}$ interagit avec une protéine Gs pour activer l'adénylate cyclase. C'est d'ailleurs le seul récepteur 5-HT dont la stimulation induit une augmentation des taux intracellulaires d'AMP cyclique [3]. En effet, celle des récepteurs $5-\mathrm{HT}_{1 \mathrm{~A}}, 5-\mathrm{HT}_{1 \mathrm{~B}}$, $5-\mathrm{HT}_{1 \mathrm{~B}}$ et $5-\mathrm{HT}_{1 \mathrm{E}}$ induit au con- traire une diminution de l'activité adénylase cyclase suite à l'activation d'une protéine $\mathrm{Gi}$ [4]. Dans le groupe des récepteurs 5 -HT, le type 5 - $\mathrm{HT}_{1 \mathrm{C}}$ se distingue de tous les autres de par son système de transduction puisqu'il est couplé, comme le récepteur $5-\mathrm{HT}_{2}$, à la phospholipase C. D'ailleurs, ces deux récepteurs $5-\mathrm{HT}_{1 \mathrm{C}}$ et $5-\mathrm{HT}_{2}$ sont très proches, tant au niveau de leurs propriétés pharmacologiques que de leurs caractéristiques moléculaires [5]. A côté de ces couplages à des systèmes de seconds messagers, les récepteurs de la 5-HT dont la stimulation provoque l'activation de protéines $\mathrm{G}$ sont également couplés à des conductances ioniques (Tableau I). C'est ainsi, par exemple, que l'activation de protéines $G$ différentes provoque tantôt l'ouverture d'une conductance potassique (couplée au récepteur $5-\mathrm{HT}_{1 \Lambda}$ ) tantôt au contraire la fermeture d'une autre conductance spécifique du $\mathrm{K}^{+}$ (couplée aux récepteurs $5-\mathrm{HT}_{\mathrm{IC}}$ et 5-HT ${ }_{2}$ ) (Tableau I, figure 1).

Les connaissances actuelles sur les récepteurs couplés aux protéines $G$ découlent des travaux qui ont été réalisés d'abord sur les récepteurs $\beta$ adrénergiques et muscariniques. Tous ces récepteurs sont constitués d'une protéine unique comportant sept domaines hydrophobes probablement localisés dans la membrane plasmique sous forme d'hélices $\alpha$ (figure 2). L'extrémité $\mathrm{N}$-terminale est situce à l'extérieur de la cellule et porte des sites de glycosylation. L'extrémité Cterminale se trouve dans le cytoplasme et comporte fréquemment une cystéine qui peut être palmitoylée, permettant ainsi un ancrage supplémentaire dans la membrane. Le site de liaison des ligands est probablement situé au niveau des domaines transmembranaires, impliquant divers acides aminés localisés sur plusieurs hélices (voir l'article de M. Hibert, p. 31 de ce numéro) (figure 3). Les boucles cytoplasmiques et la partie Cterminale participent à la reconnaissance de la sous-unité $\alpha$ des protéines G. Enfin, on trouve dans ces domaines des acides aminés hydroxylés (sérine, thréonine, tyrosine) qui peuvent être phosphorylés par diverses kinases (protéine kinase A et protéine kinase $\mathrm{C}$ en particulier). Alors que les domaines transmembranaires 
Tableau I

PRINCIPALES CARACTÉRISTIQUES DES RÉCEPTEURS CENTRAUX DE LA 5-HT

\begin{tabular}{|c|c|c|c|c|c|}
\hline Récepteur & Radioligands & Agonistes & Antagonistes & Couplage & $\begin{array}{l}\text { Principales } \\
\text { localisations }\end{array}$ \\
\hline $5-\mathrm{HT}_{1 \mathrm{~A}}$ & $\begin{array}{l}{\left[{ }^{3} \mathrm{H}\right] 8-\mathrm{OH}-\mathrm{DPAT}} \\
{\left[{ }^{3} \mathrm{H}\right] \text { lpsapirone }}\end{array}$ & $\begin{array}{l}\text { 8-OH-DPAT } \\
\text { Buspirone } \\
\text { Ipsapirone }\end{array}$ & $\begin{array}{l}\text { Spipérone } \\
\text { Propranolol }\end{array}$ & $\begin{array}{l}\text { Adénylate cyclase }(-) \\
\text { Canal } \mathrm{K}+(+1 \\
\text { Canal } \mathrm{Ca}^{2+}(-)\end{array}$ & $\begin{array}{l}\text { Structures limbiques } \\
\text { Noyaux du raphé }\end{array}$ \\
\hline $5-\mathrm{HT}_{1 \mathrm{~B}}$ & $\begin{array}{l}\text { [125|]lodocyanopindolol } \\
{[3 \mathrm{H}] 5-\mathrm{HT}} \\
\text { S-CM-G[125I]TNH }\end{array}$ & $\begin{array}{l}\text { RU } 24969 \\
\text { CP } 93,129 \\
\text { Sumatriptan }\end{array}$ & $\begin{array}{l}\text { LM } 21009 \\
(-) \text { Pindolol }\end{array}$ & Adénylate cyclase (-) & $\begin{array}{l}\text { Structures } \\
\text { extrapyramidales }\end{array}$ \\
\hline $5-\mathrm{HT}_{1 \mathrm{C}}$ & $\begin{array}{l}\text { [3HIMésulergine } \\
{[125] \text { LSD }}\end{array}$ & $\begin{array}{l}\alpha \text {-méthyl-5-HT } \\
\text { DOB } \\
\text { DOM } \\
\text { DOI }\end{array}$ & $\begin{array}{l}\text { Ritansérine } \\
\text { Mésulergine }\end{array}$ & $\begin{array}{l}\text { IP3/DG }(+) \\
\text { Canal } K+(-)\end{array}$ & Plexus choroïdes \\
\hline $5-\mathrm{HT}_{1 \mathrm{D}}$ & {$[3 \mathrm{H}] 5-\mathrm{HT}$} & $\begin{array}{l}\text { RU } 24969 \\
\text { Sumatriptan }\end{array}$ & LM 21009 & Adénylate cyclase (-) & $\begin{array}{l}\text { Structures } \\
\text { extrapyramidales }\end{array}$ \\
\hline $5-\mathrm{HT}_{2}$ & $\begin{array}{l}{\left[{ }^{3} \mathrm{H}\right] \text { Kétansérine }} \\
{\left[{ }^{3} \mathrm{H}\right] \text { Spipérone }}\end{array}$ & $\begin{array}{l}\alpha \text {-méthyl 5-HT } \\
\text { DOB } \\
\text { DOM } \\
\text { DOI }\end{array}$ & $\begin{array}{l}\text { Kétansérine } \\
\text { Spipérone } \\
\text { Ritansérine }\end{array}$ & $\begin{array}{l}\text { IP3/DG }(+) \\
\text { Canal } K^{+}(-)\end{array}$ & Cortex frontal \\
\hline $5-\mathrm{HT}_{3}$ & $\begin{array}{l}{[3 \mathrm{H}] \text { Zacopride }} \\
{[3 \mathrm{H}] \mathrm{GR} 65630} \\
{[3 \mathrm{H}] \mathrm{Granisé} \text { tron }} \\
{[3 \mathrm{H}] \text { Quipazine }}\end{array}$ & $\begin{array}{l}\text { 2-méthyl-5-HT } \\
\text { Phénylbiguanide } \\
\text { 3-chloro- } \\
\text { phénylbiguanide }\end{array}$ & $\begin{array}{l}\text { Zacopride } \\
\text { Ondansétron } \\
\text { Granisétron } \\
\text { Tropisétron } \\
\text { MDL } 72222\end{array}$ & Canal $\mathrm{Na}^{+}, \mathrm{K}^{+}, \mathrm{Ca}^{2+}(+1$ & $\begin{array}{l}\text { Brain stem (NTS) } \\
\text { Cortex entorhinal } \\
\text { Amygdale }\end{array}$ \\
\hline $5-\mathrm{HT}_{4}$ & [3H]GR 113808 & $\begin{array}{l}\text { Cisapride } \\
\text { Renzapride }\end{array}$ & $\begin{array}{l}\text { DAU } 6285 \\
\text { DAU } 6215 \\
\text { SDZ } 205557 \\
\text { GR } 113808\end{array}$ & $\begin{array}{l}\text { Adénylate cyclase }(+) \\
\text { Canal } \mathrm{K}+(-)\end{array}$ & $\begin{array}{l}\text { Collicules } \\
\text { Hippocampe } \\
\text { Substance noire }\end{array}$ \\
\hline
\end{tabular}

Parmi les agonistes et les antagonistes, certains ont été sélectionnés pour la synthèse de dérivés radioactifs (radioligands) en vue du marquage de tel ou tel récepteur dans des membranes ou des coupes (autoradiographie) de système nerveux central (SNC). Les couplages avec les systèmes de seconds messagers et les conductances ioniques sont tantôt positifs (+), tantôt négatifs (-). 8-OH-DPAT: 8-hydroxy-2(di-n-propylamino)tétraline ; S-CM-G-TNH2 : sérotonine-O-carboxy-méthyl-glycyl-tyrosinamide ; LSD : diéthylamide de l'acide lysergique; GR 65630: (5-méthyl-1H-imidazol-4-yl)-1-(1-méthyl-1H-indol-3-yl)-1-propanone; RU 24969: 5-méthoxy-3-(1,2,3,6-tétrahydro-4-piridinyl)-1H-indole; CP 93, 129 : 3-(1,2,5,6-tétrahydropyrid-4-yl) pyrrolo [3,2-b] pyrid-5-one; DOB : 1-12,5-diméthoxy-4-bromophényl)-2-aminopropane; DOM： 1-12,5-diméthoxy-4-méthyl-phényl)-2-amino-propane ; DOI: 1-12, 5-diméthoxy-4-iodo-phényl)-2-aminopropane ; LM 21009: (-)-4-(3-ter-butyl-amino-2-hydroxypropoxyl)-indol-2-carbonic acid isopropylester ; $M D L$ 72222 : $1 \alpha H, 3 \alpha, 5 \alpha H$-tropan-3-yl-3,5-dichloro-benzoate ; DAU 6285 : N-(endo-6-méthoxy-8-méthyl-8-azabicyclo [3.2.1] oct-3-yl)-2,3-dihydro-2-oxo-1H-benzimidazole-1 carboxylate; DAU 6215: N-(endo-8-méthyl-8-azabicyclol3.2.1]-oct-3-yl)-2,3-dihydro-2-oxo-1H-benzimidazol-1-carboxamide; SDZ 205557: 2-méthoxy-4-amino-5-chloro-benzoic acid-2-(diéthylaminol éthyl ester ; IP3: inositol triphosphate; DG : diacyl-glycérol (produits de l'hydrolyse des phospho-inositides par la phospholipase C activée par la stimulation des récepteurs); NTS: noyau du tractus solitaire.

sont relativement conservés avec des homologies comprises entre 30 et 99 \% d'un récepteur à un autre dans la famille des récepteurs couplés aux protéines $\mathrm{G}$, les parties $\mathrm{N}$ - et C-terminales et surtout la troisième boucle cytoplasmique sont beaucoup plus variables.

Excepté le type $5-\mathrm{HT}_{4}$, tous les récepteurs de la 5-HT couplés aux protéines $\mathrm{G}$ qui ont d'abord été identifiés par les pharmacologues ont vu leurs $\mathrm{ADNc}$ clonés et séquencés. Ils $\mathrm{m} / \mathrm{s} n^{\circ} 1 \mathrm{vol}$. 9, janvier 93 satisfont aux règles générales qui viennent d'être énoncées à propos des récepteurs de cette famille (figure 1). D'ailleurs, les gènes des récepteurs de la 5-HT ont été le plus souvent clonés en tirant parti de l'homologie de séquence transmembranaire existant dans la famille des récepteurs couplés aux protéines $G$.

Le premier gène d'un récepteur de la 5-HT à avoir été cloné est celui du récepteur $5-\mathrm{HT}_{1 \mathrm{~A}}$ humain ( $\mathrm{Ta}$ bleau II). En criblant à haute strin- gence une banque génomique humaine avec une sonde $\beta 2$-adrénergique, les auteurs espéraient "pêcher" le gène du récepteur $\beta 1$-adrénergique ; en fait, ils ont ainsi isolé un gène qui ne codait pas pour un récepteur $\beta$-adrénergique [6], mais qui s'est avéré plus tard être le gène codant pour le récepteur $5-\mathrm{HT}_{1 \mathrm{~A}}$ [7]. Le gène correspondant chez le rat a été obtenu de la même manière, et sa séquence est d'ailleurs très peu différente de celle du gène humain [8]. 


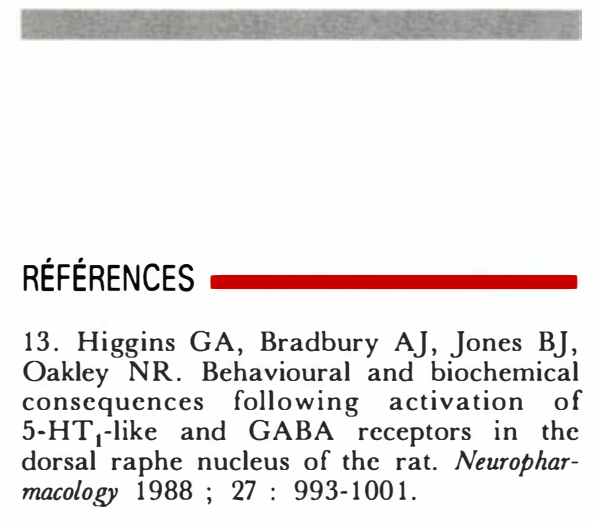

14. Hen R. Of mice and flics : commonalities among 5-HT receptors. Trends Pharmacol Sci 1992 ; 13 : 160-5.

15. Hamblin MW, Metcalf MA. Primary structure and functional characterization of a human 5-HT $\mathrm{H}_{1 \mathrm{D}}$-type serotonin receptor. Mol Pharmacol 1991 ; 40 : 143-8.

16. Weinshank RL, Zgombick JM, Macchi MJ, Branchek TA, Hartig PR. Human serotonin $1 \mathrm{D}$ receptor is encoded by a subfamily of two distinct genes : 5-HT 10 and 5-HT $1 \mathrm{DP}$ - Proc Natl Acad Sci USA 1992 ; $89: 3630-4$.

17. Voigt MM, Laurie DJ, Secburg $\mathrm{PH}$, Bach A. Molecular cloning and characterization of a rat brain cDNA encoding a 5-hydroxytryptamine ${ }_{1 \mathrm{~B}}$ receptor. $E M B O \mathrm{~J}$ $1991 ; 10: 4017-23$.

18. Maroteaux L, Saudou F, Amlaiky N, Boschert U, Plassat JL, Hen R. The mouse $5-\mathrm{HT}_{1 \mathrm{~B}}$ serotonin receptor : cloning, functional expression and localization in motor control centers. Proc Natl Acad Sci USA $1992 ; 89$ : 3020-4.

19. Bach AWJ, Unger L, Wozny M, Seeburg $\mathrm{PH}$. A new member of the serotonin receptor family: structure and functional expression of a 5- $\mathrm{HT}_{111}$-like receptor. International symposium Serotonin 1991-5-hydroxytryptamine-CNS receptors and brain function. Birmingham UK, 1991; 58 : 28 (abstr).

20. Julius D, MacDermott AB, Axel $R$, Jessell TM. Molecular characterization of a functional cDNA encoding the serotonin IC receptor. Science 1988 ; 241 : 558-64.

21. Saltzman AG, Morse B, Whitman MM, Ivanshchenko Y, Jaye M, Felder S. Cloning of the human serotonin $5-\mathrm{HT}_{2}$ and 5-HT ${ }_{1 \mathrm{C}}$ receptor subtypes. Biochem Biophys Res Commun 1991 ; 181 : 1469-78.

22. Molineaux SM, Jessell TM, Axel R, Julius D. $5-\mathrm{HT}_{1 \mathrm{C}}$ receptor is a prominent serotonin receptor subtype in the central nervous system. Proc Natl Acad Sci USA $1989 ; 86: 6793-7$.

23. Pritchett DB, Bach AWJ, Wozny M, et al. Structure and functional expression of cloned rat serotonin $5-\mathrm{HT}_{2}$ receptor. EMBO J $1988 ; 7: 4135-40$.

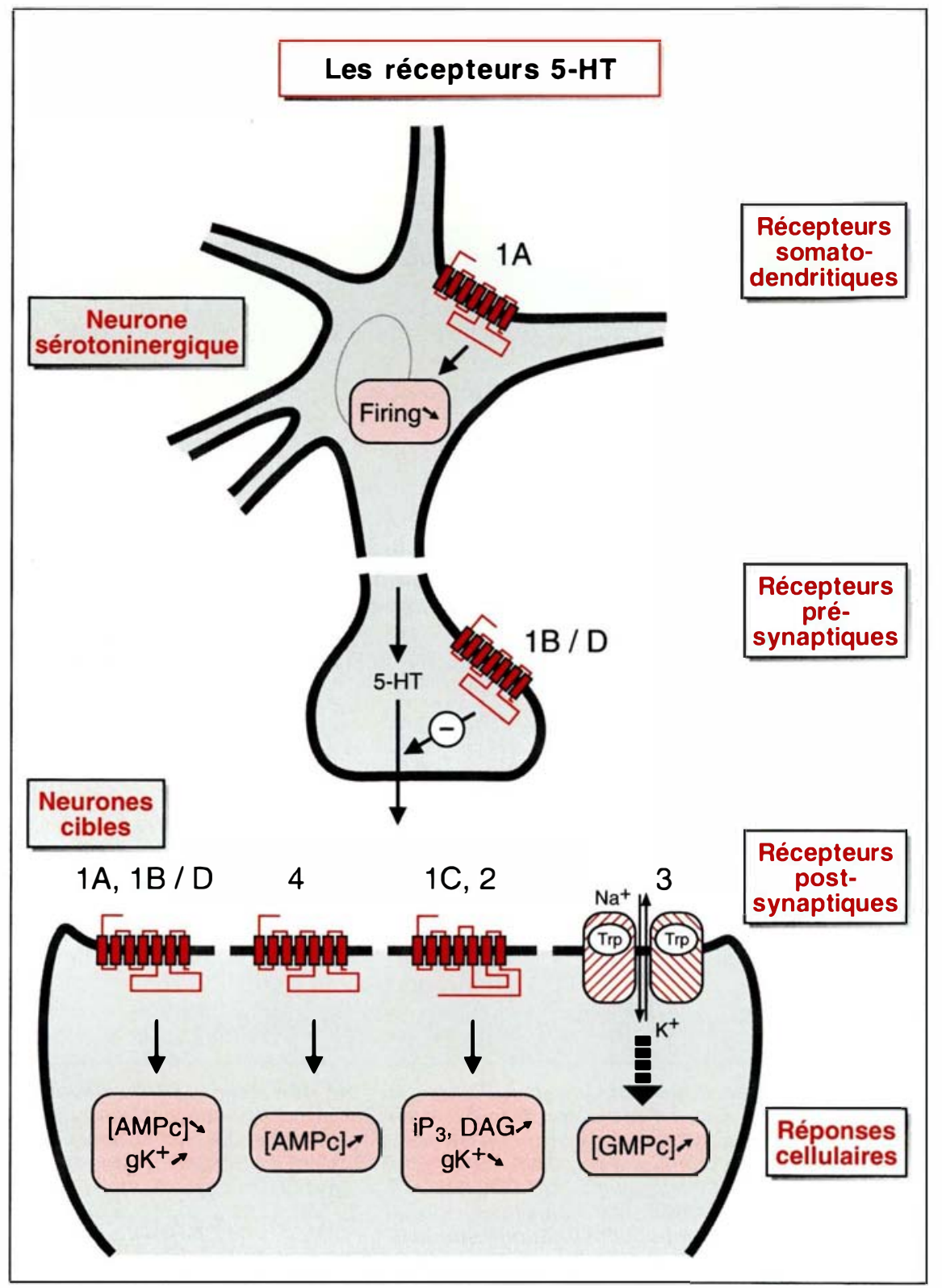

Figure 1. Localisation des différents types de récepteurs centraux de la 5-HT par rapport aux neurones sérotoninergiques. Tous les récepteurs, qu'ils soient (5-HT $\left.{ }_{1 A}, 5-H T_{1 B}, 5-H T_{1 C}, 5-H T_{10}, 5-H T_{2}, 5-H T_{4}\right)$, ou non $\left(5-H T_{3}\right)_{\text {, }}$ couplés à des protéines $G$ sont situés sur les cibles postsynaptiques des neurones sérotoninergiques. En outre, le récepteur 5-HT ${ }_{1 A}$ est également présent sur les somas et les dendrites de ces neurones lautorécepteurs somatodendritiques) tandis que les récepteurs 5-HT $10 / 5-H T_{10}$ sont situés sur leurs terminaisons (autorécepteurs présynaptiques). La stimulation des autorécepteurs 5-HT ${ }_{1 A}$ provoque une inhibition de l'activité électrique (firing) des neurones sérotoninergiques; celle des autorécepteurs $5-H T_{18} / 5-H T_{10}$ déclenche un frein de la libération de 5-HT à partir des terminaisons. La stimulation des récepteurs couplés aux protéines $G$ provoque l'activation $(+)$ ou l'inhibition $(-)$ de systèmes de seconds messagers ou de conductances ioniques (gK notamment) ; celle des récepteurs $5-\mathrm{HT}_{3}$ se traduit par l'ouverture d'un canal pour les ions $\mathrm{Na}^{+}$et $\mathrm{K}^{+}$. La dépolarisation qui en résulte entraîne finalement une augmentation des concentrations intracellulaires de $\mathrm{Ca}^{2+}$ et de GMP cyclique. 
Dans les deux cas, il existe une forte homologie avec le récepteur $\beta 2$-adrénergique; soulignons par exemple qu'au niveau du $6^{\mathrm{e}}$ domaine transmembranaire, les récepteurs $5-\mathrm{HT}_{1 \Lambda}$ et $\beta 2$-adrénergique ont en commun 20 acides aminés sur 25. De plus, les gènes codant pour ces deux récepteurs sont également dépourvus d'introns. Exprimé dans diverses lignées cellulaires, le récepteur $5-\mathrm{HT}_{1 \wedge}$ présente les mêmes caractéristiques pharmacologiques que celles du récepteur "naturel " dans des membranes cérébrales. La stimulation du récepteur dans les cellules transfectées conduit à une inhibition de l'activité adénylate cyclase, comme dans le tissu cérébral. Cependant, dans certaines lignées cellulaires, le récepteur $5-\mathrm{HT}_{1 \mathrm{~A}}$ peut également être couplé à la phospholipase C [9]. Les études d'hybridation in situ ont montré que l'ARNm codant pour le récepteur $5-\mathrm{HT}_{1 \mathrm{~A}}$ est présent dans les mêmes régions qui contiennent le récepteur lui-même repéré soit par la liaison d'un radioligand sélectif (notamment le $\left[{ }^{3} \mathrm{H}\right] 8$-hydroxy-2-[di- $n$ propylamino] tétraline ou $\left[{ }^{3} \mathrm{H}\right] 8$ OH-DPAT), soit par des anticorps spécifiques [10]. On trouve le récepteur $5-\mathrm{HT}_{1 \mathrm{~A}}$ dans les structures limbiques comme l'hippocampe, le septum, l'amygdale, le cortex frontal, etc., qui jouent un rôle clé dans le contrôle de l'humeur et des émotions. Or certains ligands des récepteurs $5-\mathrm{HT}_{1 \wedge}$ sont des anxiolytiques et des antidépresseurs potentiels. Nous aurons l'occasion d'y revenir dans la dernière partie de cette revue. Une autre région qui contient une forte densité à la fois de récepteurs $5-\mathrm{HT}_{1 \Lambda}$ et d'ARNm correspondant est constituée par les noyaux antérieurs (dorsal et médian) du raphé, où sont localisés l'essentiel des corps cellulaires des neurones à l'origine de l'innervation sérotoninergique centrale. En fait, des études impliquant soit un double marquage immunocytochimique [11], soit la lésion sélective des neurones sérotoninergiques suite à l'administration intracérébrale d'une neurotoxine spécifique, la 5,7-dihydroxytryptamine [12], ont clairement démontré que les récepteurs $5-\mathrm{HT}_{1 \mathrm{~A}}$ sont situés à la surface des somas et des dendrites de ces neurones dans les noyaux antérieurs

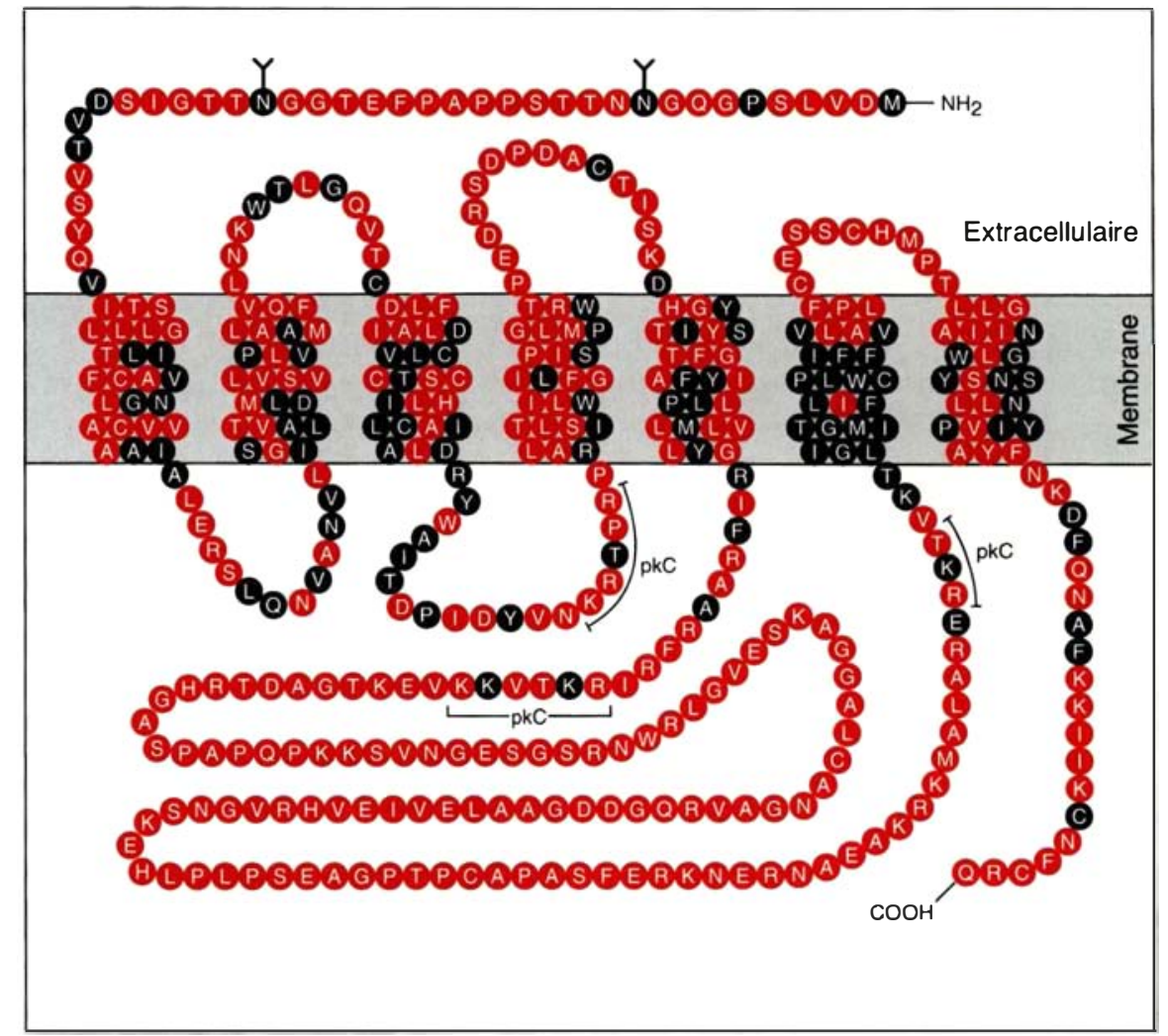

Figure 2. Séquence en acides aminés du récepteur 5-HT 1 humain. Les sites consensus pour la protéine kinase $C$ sont situés dans les $2^{\theta}$ et $3^{\theta}$ boucles intracytoplasmiques, tandis que les deux asparagines glycosylées sont localisées dans la partie $\mathrm{N}$-terminale extracellulaire. Les acides aminés en noir sont retrouvés dans la séquence du récepteur $5-H T_{1 C}$. Ce type de représentation montre clairement que l'homologie de séquence entre ces deux récepteurs est beaucoup plus grande dans les domaines transmembranaires.

du raphé (figure 1). Ces récepteurs (qu'on appelle des autorécepteurs parce qu'ils sont reconnus par le neuromédiateur synthétisé dans les neurones qui les portent) participent directement au contrôle de l'activité électrique et métabolique des neurones sérotoninergiques. Leur stimulation (y compris par la 5-HT qui peut être libérée au niveau somatodendritique) déclenche en effet une diminution à la fois de la fréquence de décharge de ces neurones et de la libération de la 5-HT à partir de leurs terminaisons. C'est d'ailleurs en stimulant ces autorécepteurs somatodendritiques que certains agonistes $5-\mathrm{HT}_{1 \wedge}$ exercent leurs effets anxiolytiques [13].

D'autres récepteurs de la 5-HT sont aussi localisés, au moins en partie, sur les neurones sérotoninergiques, et peuvent donc être appelés des autorécepteurs. Il s'agit des récepteurs
$5-\mathrm{HT}_{1 \mathrm{~B}}$ (surtout chez le rat et la souris) et $5-\mathrm{HT}_{1 \mathrm{D}}$ (surtout chez les autres mammifères y compris l'homme) sur les terminaisons de ces neurones (figure 1). Leur stimulation déclenche un frein qui se traduit par une diminution de la libération de la 5-HT. D'une manière générale, les récepteurs $5-\mathrm{HT}_{1 \mathrm{~B}}$ et $5-\mathrm{HT}_{1 \mathrm{D}}$ semblent situés préférentiellement sur les terminaisons de diverses populations neuronales où ils contrôleraient la libération de nombreux neuromédiateurs dans le système nerveux central (acétylcholine, GABA, enképhalines, etc.). D'ailleurs, contrairement aux observations que nous avons rapportées dans le cas des récepteurs $5-\mathrm{HT}_{1 \wedge}$, la distribution des récepteurs $5-\mathrm{HT}_{1 \mathrm{~B}}$ et $5-\mathrm{HT}_{1 \mathrm{D}}$ ne correspond pas du tout à celle de leurs ARNm. Ainsi, l'hybridation in situ montre que les ARNm codant pour les récepteurs $5-\mathrm{HT}_{1 \mathrm{~B}}$ et $5-\mathrm{HT}_{11}$ 


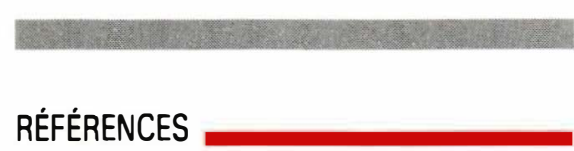

24. Julius D, Huang $\mathrm{KN}$, Livclli $\mathrm{T}$, Axcl R, Jesscll TM. The 5- $\mathrm{HT}_{2}$ reccptor defines a family of structurally distinct but functionally conserved serotonin receptors. Proc Natl Acad Sci USA 1990 ; 87 : 928-32.

25. Mengod G, Pompeiano M, MartinczMir MI, Palacios JM. Localization of the mRNA for the $5-\mathrm{HT}_{2}$ receptor by in situ hybridization histochemistry. Correlation with the distribution of reccptor sitcs. Brain Res 1990 ; 524 : 139-43.

26. Janssen PAJ, Niemegecrs CJE, Awouters F, Schellckens KHL, Megens AAHP, Mcert TF. Pharmacology of risperidone (R 64 766), a new antipsychotic with serotonin- $\mathrm{S}_{2}$ and dopamine- $\mathrm{D}_{2}$ antagonistic properties. J Pharmacol Exp Ther 1988; 244 : 685-93.

27. Levy FO, Gudermann T, Birnbaumer M, Kaumann AJ, Birnbaumer L. Molecular cloning of a human gene (S31) encoding a novel serotonin receptor mediating inhibition of adenylyl cyclasc. FEBS Lett 1992 ; 296 : 201-6.

28. McAllister G, Charlesworth A, Snodin C, et al. Molccular cloning of a serotonin receptor from human brain $\left(5-\mathrm{HT}_{1 \mathrm{E}}\right)$ : a fifth 5-HT, -like subtype. Proc Natl Acad Sci USA 1992 ; 89 : 5517-21.

29. Witz P, Amlaiky N, Plassat JL, Maroteaux L, Borrclli E, Hen R. Cloning and charactcrization of a drosophila scrotonin receptor that activates adenylatc cyclase. Proc Natl Acad Sci USA 1990; 87 : 8940-4.

30. Yakel JL, Shao XM, Jackson MB. The selectivity of the channcl coupled to the 5- $\mathrm{HT}_{3}$ reccptor. Brain Res 1990 ; 533 : 46-52.

31. Maricq AV, Peterson AS, Brake AJ, Myers RM, Julius D. Primary structure and functional expression of the $5-\mathrm{HT}_{3}$ reccptor, a serotonin-gated ion channel. Science $1991 ; 254: 432-7$

32. Laporte AM, Kosciclniak T, Ponchant M, Vergé D, Hamon M, Gozlan H. Quantitative autoradiographic mapping of $5-\mathrm{HT}_{3}$ receptors in the rat CNS using [125I]iodo-zacopride and $\left[{ }^{3} \mathrm{H}\right]$ zacopride as radioligands. Synapse $1992 ; 10: 271-81$.

33. Slcight AJ, Pierce PA, Schmidt AW, Hekmatpanah CR, Peroutka SJ. The clinical utility of scrotonin reccptor active agents in neuropsychiatric disease. In : Peroutka SJ, cd. Serotonin Receptor Subtypes : Basic and Clinical Aspects. New York : Wiley-Liss Inc, 1991: 211-27.

34. Gozlan H, Demaret JP. Apports de la chimie et de la biologic moléculaire à la connaissance des réccpteurs $5-\mathrm{HT}_{1 \mathrm{~A}}$ centraux : conception d'un antagoniste spécifique à l'aide de la modélisation du récepteur 5-HT 1A. Actual Chim Ther 1992; 19: $15-52$.

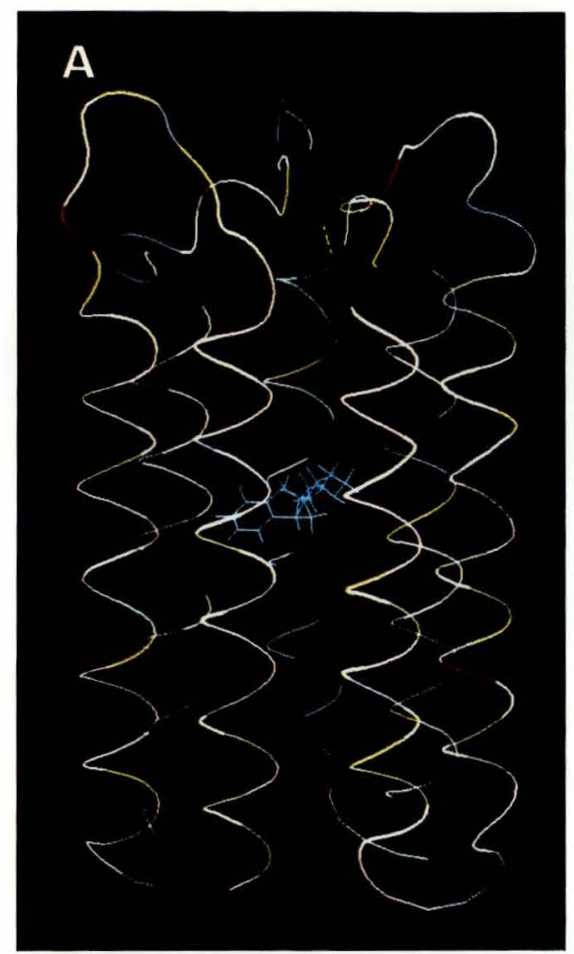

Figure 3. Modélisation graphique du récepteur 5-HT, A. Vue latérale des hélices transmembranaires. $L a$ face cytoplasmique de la membrane correspond à la partie inférieure de la figure. Le 8-OH-DPAT (voir Tableau I; en bleu sur la figure), ligand de référence des sites 5-HT, ${ }_{1 A}$ a été positionné dans son site de liaison le plus probable (intramembranaire). B. Coupe transversale des hélices transmembranaires au niveau du site de liaison probable du 8-OH-DPAT len orangé sur la figure). Le ligand est positionné de façon à favoriser le maximum d'interactions avec les résidus acides aminés des différentes hélices $13^{e}, 5^{\theta}$ et $6^{e}$, voir texte).

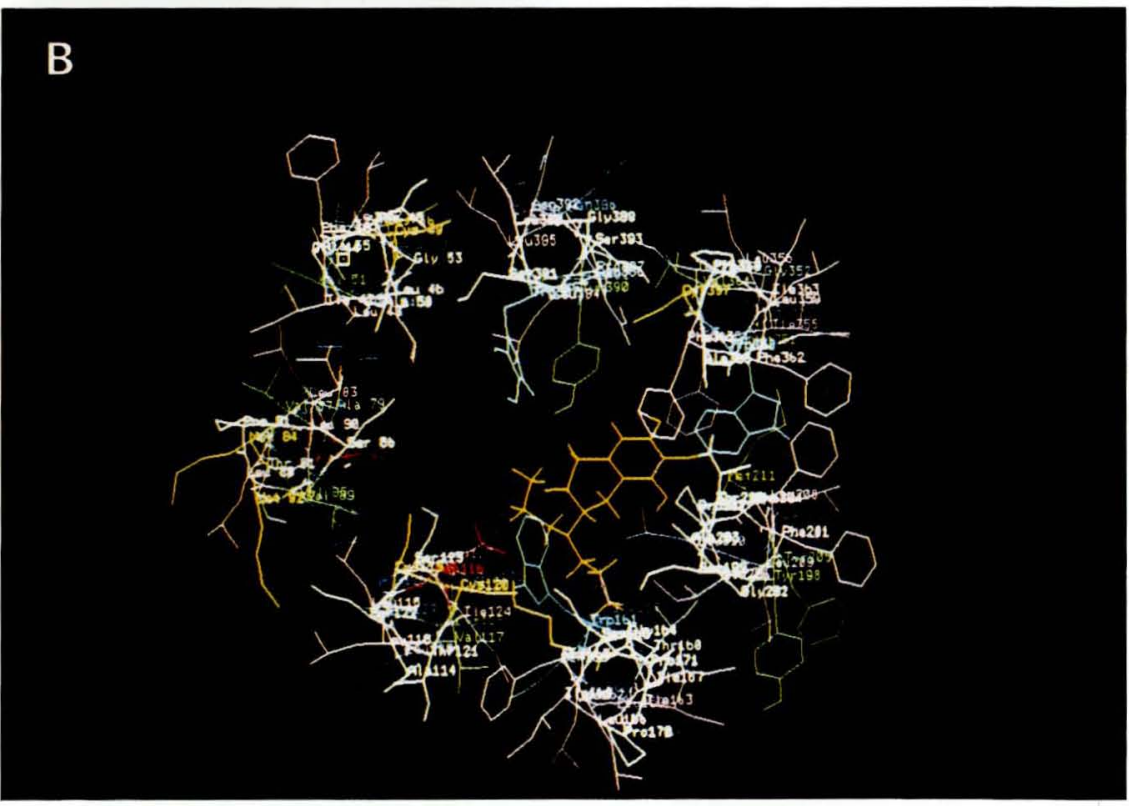

sont abondants dans le striatum alors que c'est au niveau de la substance noire et du globus pallidus que l'on trouve les plus fortes concentrations de sites de liaison 5-HT ${ }_{1 \mathrm{~B}}$ et $5-\mathrm{HT}_{1 \mathrm{D}}$. Un autre exemple concerne le cervelet : les récepteurs $5-\mathrm{HT}_{1 \mathrm{~B}}$ et $5-\mathrm{HT}_{1 \mathrm{D}}$ sont présents surtout dans les noyaux profonds alors que les ARNm sont abondants dans les cellules de Purkinje. En fait, on trouve les ARNm dans les corps cellulaires des neurones (striato-nigraux, striatopallidaux, etc.) qui se projettent justement dans les zones enrichies en récepteurs $5-\mathrm{HT}_{1 \mathrm{~B}}$ et $5-\mathrm{HT}_{1 \mathrm{D}}$ [14]. Le clonage des gènes de ces récepteurs chez l'homme a montré qu'il existait deux sous-types pour la classe $5-\mathrm{HT}_{1 \mathrm{D}}$, appelés $5-\mathrm{HT}_{1 \mathrm{D} \alpha}$ et $5-\mathrm{HT}_{1 \mathrm{D} \beta}$ [15, 16] (Tableau II). L'homologie de séquence atteint $77 \%$ au niveau des 


\begin{tabular}{|c|c|c|c|c|c|c|c|c|c|c|c|c|}
\hline & & & & $\begin{array}{l}\text { INCIPALES CA } \\
\text { POUR LES DIF } \\
\text { DE LA } 5-\end{array}$ & $\begin{array}{l}\text { TARACTÉF } \\
\text { ARÁRENT } \\
\text { FFE COUF }\end{array}$ & $\begin{array}{l}\text { Tableau } \\
\text { RISTIOL } \\
\text { ES CLA } \\
\text { PLÉS A }\end{array}$ & $\begin{array}{l}\| \\
\text { JES D } \\
\text { ASSES } \\
\text { DES }\end{array}$ & $\begin{array}{l}\text { EES G } \\
\text { DE } \\
\text { PRO }\end{array}$ & $\begin{array}{l}\text { ĖNES } \\
\text { RÉCEF } \\
\text { TÉINES }\end{array}$ & $\begin{array}{l}\text { CODANT } \\
\text { TEURS } \\
\text { G }\end{array}$ & & \\
\hline & Espèce & A.A. & Intron & Locus & $\mathrm{N}$-term & Glyco & $1-3$ & PKA & PKC & C-term & ARNm & Références \\
\hline $5-\mathrm{HT}_{1 \mathrm{~A}}$ & $\begin{array}{l}\text { Homme } \\
\text { Rat }\end{array}$ & $\begin{array}{l}421 \\
422\end{array}$ & $\begin{array}{l}0 \\
0\end{array}$ & $5 q 11.2-q 13$ & $\begin{array}{l}36 \\
36\end{array}$ & $\begin{array}{l}2 \\
3\end{array}$ & $\begin{array}{l}129 \\
129\end{array}$ & & $\begin{array}{l}3 ? \\
2\end{array}$ & 19 (cys) & $\begin{array}{c}6,0 \\
3,9(e t) 3,3-3,6)\end{array}$ & $\begin{array}{l}{[6]} \\
{[8]}\end{array}$ \\
\hline $5-\mathrm{HT}_{18}$ & $\begin{array}{l}\text { Rat } \\
\text { Souris }\end{array}$ & \begin{tabular}{|l|}
386 \\
386
\end{tabular} & $\begin{array}{l}0 \\
0\end{array}$ & & $\begin{array}{l}45 \\
45\end{array}$ & $\begin{array}{l}2 \\
2\end{array}$ & $\begin{array}{l}85 \\
85\end{array}$ & $\begin{array}{l}2 \\
2\end{array}$ & $\begin{array}{l}1 \\
1\end{array}$ & $\begin{array}{l}18 \text { (cys) } \\
18 \text { (cys) }\end{array}$ & $\begin{array}{c}6,0-8,0 \\
6,0\end{array}$ & $\begin{array}{l}{[17]} \\
{[18]}\end{array}$ \\
\hline $5-\mathrm{HT}_{1 \mathrm{D} \alpha}$ & $\begin{array}{l}\text { Homme } \\
\text { Rat }\end{array}$ & \begin{tabular}{|l|}
377 \\
376 \\
374
\end{tabular} & $\begin{array}{l}0 \\
0 \\
0\end{array}$ & $1 p 34.3-36.3$ & $\begin{array}{l}38 \\
38 \\
35\end{array}$ & $\begin{array}{l}3 \\
3 \\
3\end{array}$ & $\begin{array}{l}83 \\
82 \\
83\end{array}$ & 2 & & $\begin{array}{l}19 \text { (cys) } \\
19 \text { (cys) } \\
18 \text { (non) }\end{array}$ & & $\begin{array}{l}{[15]} \\
{[16]} \\
{[19]}\end{array}$ \\
\hline $5-\mathrm{HT}_{1 \mathrm{D \beta}}$ & Homme & 390 & 0 & $6 q 12-q 13$ & 49 & 2 & 87 & 2 & 1 & 18 (non) & 5,6 & [16] \\
\hline $5-\mathrm{HT}_{1 \mathrm{E}}$ & Homme & 365 & 0 & & 22 & 2 & 88 & 1 & 5 & 18 (cys) & 5,3 & [27] [28] \\
\hline $5-\mathrm{HT}_{4} ?$ & Droso & 564 & 0 & & 182 & 2 & 110 & & & 53 (cys) & 5,5 & [29] \\
\hline $5-\mathrm{HT}_{1 \mathrm{C}}$ & $\begin{array}{l}\text { Homme } \\
\text { Rat } \\
\text { Souris } \\
\end{array}$ & \begin{tabular}{|l|}
457 \\
460 \\
459 \\
\end{tabular} & $\begin{array}{l}\text { oui } \\
\text { oui } \\
\text { oui }\end{array}$ & $\begin{array}{l}x \\
x\end{array}$ & $\begin{array}{l}53 \\
54 \\
54 \\
\end{array}$ & $\begin{array}{l}1 \\
1 \\
1 \\
\end{array}$ & $\begin{array}{l}75 \\
77 \\
77 \\
\end{array}$ & $\begin{array}{l}2 \\
2 \\
2 \\
\end{array}$ & $\begin{array}{l}2 \\
2 \\
2 \\
\end{array}$ & $\begin{array}{l}87 \text { (cys) } \\
87 \text { (cys) }\end{array}$ & 5,2 & $\begin{array}{l}{[21]} \\
{[20]}\end{array}$ \\
\hline $5-\mathrm{HT}_{2}$ & $\begin{array}{l}\text { Homme } \\
\text { Rat }\end{array}$ & $\begin{array}{l}471 \\
471\end{array}$ & $\begin{array}{l}\text { oui } \\
\text { oui }\end{array}$ & $13 q 14-q 21$ & $\begin{array}{l}74 \\
74\end{array}$ & $\begin{array}{l}5 \\
5\end{array}$ & $\begin{array}{l}68 \\
68\end{array}$ & $\begin{array}{l}3 \\
3\end{array}$ & & $\begin{array}{l}87 \text { (cys) } \\
87 \text { (cys) }\end{array}$ & (2) $5,0-6,0$ & $\begin{array}{c}{[21]} \\
{[23][24]}\end{array}$ \\
\hline
\end{tabular}

A.A. = nombre d'acides aminés dans la phase de lecture; intron: 0 : aucun ; Locus : localisation chromosomique des gènes; $N$ term : nombre d'acides aminés dans la partie $N$-terminale du récepteur (extracellulaire): Glyco : nombre de résidus glycosylés dans la partie N-terminale ; I-3 : nombre d'acides aminés dans la troisième boucle intracytoplasmique ; PKA et PKC : nombre de séquences consensus pour la phosphorylation par ces deux kinases d'acides aminés hydroxylés; C-term : nombre d'acides aminés dans la partie C-terminale intracytoplasmique; (cys) : présence ou non d'une cystéine palmitoylée ; ARNm : taille (en kilobases) des ARNm correspondants.

domaines transmembranaires, et les propriétés pharmacologiques de ces deux sous-types sont pratiquement identiques. Cependant, ils ne sont pas également représentés : le récepteur $5-\mathrm{HT}_{1 \mathrm{D} \beta}$ est en effet beaucoup plus abondant que le type $5-\mathrm{HT}_{1 \mathrm{D} \alpha}$ dans le cerveau humain [2]. Chez le rat [17] et la souris [18]; l'homologue du type $5-\mathrm{HT}_{1 \mathrm{D} \beta}$ présente une séquence en acides aminés identique à $95 \%$ à celle du récepteur humain ; pourtant ses propriétés pharmacologiques le distinguent nettement du type $5-\mathrm{HT}_{11}$, d'où son appellation $5-\mathrm{HT}_{1 \text { в }}$ (Tableau II). De fait, le récepteur $5-\mathrm{HT}_{1 \mathrm{~B}}$ possède une affinité environ 100 fois plus élevée que les récepteurs $5-\mathrm{HT}_{1 \mathrm{D} \alpha}$ et $5-\mathrm{HT}_{1 \mathrm{1} \beta}$ pour certains ligands $\beta$-adrénergiques (pindolol, propranolol, penbutolol, etc.) (Tableau I). Enfin, on trouve aussi l'homologue du récepteur $5-\mathrm{HT}_{1 D \alpha}$ humain chez le rat [19], mais avec, cette fois, un profil phar- macologique typique de la famille $5-\mathrm{HT}_{1 \mathrm{D}}$. Comme chez l'homme, ce récepteur est très peu représenté dans le cerveau du rat [2].

L'expression différentielle des récepteurs de la famille $5-\mathrm{HT}_{13} / 5-\mathrm{HT}_{11}$ dans des lignées cellulaires confirme qu'ils sont tous couplés de manière négative à l'adénylate cyclase. Sur le plan pharmacologique, leur définition reste encore assez succincte du fait du manque de ligands sélectifs. Ainsi, par exemple, le sumatriptan un nouveau composé anti-migraineux se lie avec pratiquement la même affinité sur ces différents sous-types $5-\mathrm{HT}_{1 \mathrm{~B}}$ et $5-\mathrm{HT}_{1 \mathrm{D}}$. D'autres ligands permettent cependant de les distinguer (Tableau I). C'est notamment le cas de l'agoniste CP 93, 129 qui ne reconnaît que le type $5-\mathrm{HT}_{1 \mathrm{~B}}$; son affinité pour les récepteurs de la famille $5-\mathrm{HT}_{1 \mathrm{~B}} / 5-\mathrm{HT}_{1 \mathrm{D}}$ chez l'homme est en effet très faible $\left(\mathrm{K}_{\text {d }}\right.$ $\geqslant 5 \mu \mathrm{M})$.
Le clonage du gène codant pour le récepteur $5-\mathrm{HT}_{1 \mathrm{C}}[20,21]$ a montré qu'il avait peu d'homologie $(40 \%$ dans les domaines transmembranaires) avec celui des récepteurs $5-\mathrm{HT}_{1 \wedge}$ (figure 2, p. 25) et $5-\mathrm{HT}_{1 \mathrm{~B} / 11 \text { ) }}$. Du reste, contrairement aux précédents, le gène $5-\mathrm{HT}_{1 \mathrm{C}}$ possède des introns (Tableau II). L'expression dans des cellules NIH 3T3 du récepteur $5-\mathrm{HT}_{1 \mathrm{C}}$ cloné a confirmé son couplage avec la phospholipase C. L'étude de la distribution régionale de l'ARNm codant pour le récepteur $5-\mathrm{HT}_{1 \mathrm{C}}$ montre une répartition très large (noyaux du raphé, hippocampe, substance noire, locus caeruleus, moelle épinière, etc.), avec un enrichissement dans les plexus choroïdes, où l'on trouve aussi la plus forte densité de sites de liaison 5-HT ${ }_{1 C}$ [22]. Dans le noyau subthalamique, l'habénula et le septum, l'AR Nm est relativement plus abondant que le récepteur $5-\mathrm{HT}_{1 \mathrm{C}}$, laissant à penser que 
le turnover de ce récepteur y est particulièrement rapide. Au niveau des plexus choroïdes où les récepteurs $5-\mathrm{HT}_{1 \mathrm{C}}$ sont exclusivement localisés dans la membrane apicale des cellules épithéliales, la 5-HT semble affecter la synthèse et la sécrétion de diverses glycoprotéines dans le liquide céphalo-rachidien. Les récepteurs $5-\mathrm{HT}_{1 \mathrm{C}}$ joueraient donc un rôle important dans le contrôle de la composition de ce milieu. Cependant, d'autres fonctions sont sans doute également sous le contrôle de ces récepteurs; des effets anxiogènes et anorexigènes ont d'ailleurs été attribués à des agonistes (assez peu spécifiques) des récepteurs $5-\mathrm{HT}_{1 \mathrm{C}}$.

C'est avec une sonde $5-\mathrm{HT}_{1 \mathrm{C}}$ que Pritchett et al. [23] sont parvenus à cloner le gène codant pour le récepteur 5- $\mathrm{HT}_{2}$ (Tableau II). En fait, comme nous l'avons déjà souligné, les récepteurs $5-\mathrm{HT}_{1 \mathrm{C}}$ et $5-\mathrm{HT}_{2}$ possèdent des propriétés pharmacologiques très proches (Tableau I). De plus, ils sont tous les deux couplés à la phospholipase C. Au niveau des séquences, on trouve $78 \%$ d'homologie entre les récepteurs $5-\mathrm{HT}_{1 \mathrm{C}}$ et $5-\mathrm{HT}_{2}$ dans les domaines transmembranaires. Enfin, comme le gène codant pour le récepteur $5-\mathrm{HT}_{1 \mathrm{C}}$, celui du récepteur $5-\mathrm{HT}_{2}$ possèdc des introns $[21,23,24]$. La distribution de l'ARNm du récepteur 5- $\mathrm{HT}_{2}$ se superpose à celle du récepteur luimême identifié par un radioligand spécifique (par exemple la $\left[{ }^{3} \mathrm{H}\right]$ kétansérine, voir Tableau $I$ ), avec des zones très riches en l'un et l'autre comme le cortex frontal, le cortex pyriforme, le cortex entorhinal et le claustrum [25]. Le bulbe et le tubercule olfactifs, le noyau caudé et le noyau accumbens expriment aussi ce récepteur, alors que le cervelet en est dépourvu.

Les récepteurs $5-\mathrm{HT}_{2}$ semblent participer au contrôle des systèmes dopaminergiques centraux. Les antagonistes $5-\mathrm{HT}_{2}$ s'opposent en particulier aux effets extrapyramidaux induits par le blocage des récepteurs $D_{2}$, d'où la tendance actuelle à développer de nouveaux neuroleptiques ayant des potentialités à la fois antidopamine et anti-5-HT [26]. De fait, il semble que ces composés n'induisent pas de mouvements anormaux chez les schizophrènes, contrairement aux neuroleptiques " classiques" (par exemple l'halopéridol).

En dehors de ceux des grandes classes de récepteurs que nous venons de passer rapidement en revue, les $\mathrm{ADNc}$ ou les gènes d'autres récepteurs de la 5-HT viennent ou sont en passe d'être clonés (Tableau II). Ainsi Levy et al. [27] ont isolé un gène (appelé S31) dont la protéine correspond en fait au récepteur $5-\mathrm{HT}_{1 \mathrm{E}}$ [28]. Ce dernier présente une homologie de séquence qui atteint $47 \%$ lorsqu'on la compare à celle du récepteur $5-\mathrm{HT}_{1 \mathrm{D} \alpha}$, et $39 \%$ par rapport à celle du récepteur $5-\mathrm{HT}_{1 \Lambda}$. Exprimé dans des lignées cellulaires, le récepteur 5-HT ${ }_{1 E}$ contrôle négativement l'activité de l'adénylate cyclase. En plus de son affinité élevée $(\mathrm{Kd}=6,1 \mathrm{nM})$ pour la $5-\mathrm{HT}$, le récepteur $5-\mathrm{HT}_{1 \mathrm{E}}$ possède un profil pharmacologique qui le distingue nettement des autres récepteurs 5- $\mathrm{HT}_{1}$.

Parmi les récepteurs couplés aux protéines $\mathrm{G}$, nous avons déjà signalé que le type $5-\mathrm{HT}_{4}$ n'a toujours pas été cloné chez les mammiferes. Cependant, un gène codant pour un récepteur du même type, c'est-à-dire dont la stimulation provoque l'activation de l'adénylase cyclase, a été identifié chez la drosophile [29]. Il est sans doute prématuré de considérer ce récepteur comme l'homologue, chez la drosophile, du récepteur $5-\mathrm{HT}_{4}$ chez les mammifères, d'autant qu'il présente non pas sept mais huit domaines transmembranaires putatifs. Il possède en effet une longue séquence hydrophobe dans sa partie $\mathrm{N}$-terminale, que l'on ne retrouve pas dans les autres récepteurs couplés aux protéines G (Tableau II).

\section{Le récepteur-canal ionique de la 5-HT}

A côté de la grande diversité des récepteurs de la 5 -HT couplés aux protéines $\mathrm{G}$, on n'a identifié jusqu'à présent qu'un seul "récepteur-canal ionique" pour ce neuromédiateur (Tableau I, figure 1). Il s'agit du récepteur $5-\mathrm{HT}_{3}$ dont la stimulation entraîne l'ouverture d'un canal sodium/potassium [30]. Dans son fonctionnement et dans ses régulations, ce récepteur présente des similitudes avec le récepteur nicotinique de l'acétylcholine et le récepteur NMDA du glutamate [30]. D'ailleurs, le clonage d'une sous-unité du récepteur $5-\mathrm{HT}_{3}$ exprimé dans la lignée cellulaire murine NCB20 [31] confirme l'existence d'analogies entre ces différents récepteurs-canaux ioniques. Cette sous-unité (de 487 acides aminés) comporte une extrémité $\mathrm{N}$ terminale extracellulaire, quatre domaines transmembranaires et une extrémité C-terminale extracellulaire. On retrouve dans sa partie $\mathrm{N}$ terminale un pont disulfure dont l'importance a été soulignée dans le cas du récepteur nicotinique. Cette même région comporte des séquences assez voisines de celles qui sont impliquées dans la reconnaissance des antagonistes par les autres récepteurs canaux ioniques.

Dans le SNC, le récepteur $5-\mathrm{HT}_{3}$ est présent au niveau de structures limbiques (amygdale, hippocampe, cortex entorhinal), mais il est surtout abondant dans le complexe dorsovagal, qui comporte en particulier le noyau du tractus solitaire, et dans les couches superficielles des cornes dorsales de la moelle épinière [32]. Aussi bien dans le noyau du tractus solitaire que dans la moelle épinière, les récepteurs $5-\mathrm{HT}_{3}$ sont situés sur des fibres afférentes (respectivement les fibres vagales et les fibres sensorielles primaires). La stimulation des récepteurs $5-\mathrm{HT}_{3}$ entraîne une dépolarisation, mais cette réponse s'atténue très rapidement (désensibilisation). Quoi qu'il en soit, il semble que cette localisation soit en relation avec la capacité des ligands des récepteurs $5-\mathrm{HT}_{3}$ à moduler la libération de nombreux neuromédiateurs dans le système nerveux central (et aussi à la périphérie).

Jusqu'à présent, les études pharmacologiques ont mis en évidence non pas une hétérogénéité des récepteurs $5-\mathrm{HT}_{3}$, mais des variations d'une espèce à l'autre. Cependant, il n'existe pas encore de données sur les éventuelles différences interspécifiques dans les séquences de ces récepteurs. De plus, les autres récepteurs-canaux ioniques étant des complexes multimériques, il est probable que d'autres sous-unités que celle qui a été clonée récemment [31] participent à la constitution du récepteur $5-\mathrm{HT}_{3}$. Il y a donc encore beaucoup à attendre de 
la biologie moléculaire pour une connaissance plus approfondie de ce récepteur.

\section{Potentialités}

thérapeutiques des ligands des récepteurs de la 5-HT

Compte tenu de la pluralité des fonctions impliquant la 5-HT, il n'est pas surprenant a priori de trouver des ligands des récepteurs de ce neuromédiateur parmi des médicaments aussi divers que des anxiolytiques (notamment la buspirone, un agoniste partiel des récepteurs $5-\mathrm{HT}_{1 \Lambda}$ ), des antimigraineux (par exemple le sumatriptan, un agoniste des récepteurs $5-\mathrm{HT}_{1 \mathrm{~B}}$ et $\left.5-\mathrm{HT}_{1 \mathrm{D}}\right)$ et des antiémétiques (les antagonistes des récepteurs $5-\mathrm{HT}_{3}$ comme l'ondansétron et le granisetron). En fait, les potentialités thérapeutiques des ligands des différentes classes des récepteurs de la 5-HT sont tout à fait considérables [33], et les industriels de la pharmacie font actuellement de gros efforts pour mettre au point des ligands de ces récepteurs qui soient encore plus sélectifs et efficaces.

- Dans le domaine des anxiolytiques, plusieurs récepteurs semblent être concernés puisque des effets de type anxiolytique ont été obtenus chez l'animal avec des agonistes des récepteurs 5-HT ${ }_{1 \wedge}$ (beaucoup plus sélectifs que la buspirone), des antagonistes des récepteurs $5-\mathrm{HT}_{1 \mathrm{C}}$ et $5-\mathrm{HT}_{2}$, et des antagonistes des récepteurs 5- $\mathrm{HT}_{3}$ [33]. L'intérêt de ces nouveaux composés par rapport aux benzodiazépines est évident. Contrairement à ces dernières et à d'autres tranquillisants qui se fixent également sur les mêmes sites, les ligands des récepteurs de la 5-HT n'induisent ni accoutumance ni dépendance. De plus, ils ne sont pas sédatifs, ni myorelaxants, ni, surtout, amnésiants. Au contraire, les antagonistes $5-\mathrm{HT}_{3}$ semblent stimuler la fonction mnésique dans divers tests appropriés chez l'animal. Par ailleurs, les antagonistes $5-\mathrm{HT}_{2}$ stimulent la fonction de récupération en augmentant les taux de sommeil lent profond (stades III et IV) aussi bien chez l'animal que chez l'homme. Enfin, des résultats encourageants montrent qu'aussi bien les agonistes des récep$m / s n^{\circ} 1$ vol. 9, janvier 93 teurs $5-\mathrm{HT}_{\text {॥ }}$ que les antagonistes des récepteurs $5-\mathrm{HT}_{2}$ et $5-\mathrm{HT}_{3}$ peuvent diminuer la consommation d'alcool chez les patients alcooliques, sans doute en partie via leurs effets anxiolytiques. On peut donc s'attendre à ce que des ligands de ce type soient développés pour le traitement de l'anxiété pathologique au cours des prochaines années.

- Dans le domaine des antidépresseurs, l'étude des récepteurs de la 5-HT peut également déboucher sur la mise au point de molécules encore plus efficaces étant donné que la thérapeutique actuelle fait largement appel aux inhibiteurs de la recapture de ce neuromédiateur. Ces composés augmentent la concentration extracellulaire de la 5-HT, et entraînent donc la stimulation des diverses classes de récepteurs spécifiques par le neuromédiateur endogène. Dans ce contexte, il convient de rappeler que certains de ces récepteurs sont des autorécepteurs dont l'activation déclenche un contrôle inhibiteur de la transmission sérotoninergique centrale (figure 1), c'est-à-dire l'inverse du but recherché avec les bloquants de recapture. Selon certains auteurs, la stimulation des autorécepteurs par le neuromédiateur endogène en excès s'opposerait ainsi à l'action thérapeutique des antidépresseurs. D'ailleurs, le délai d'action antidépressive des inhibiteurs de recapture de la 5-HT ( $\geqslant 2$ semaines) correspond au temps nécessaire à la désensibilisation des autorécepteurs [4]. Dans ces conditions, on comprend pourquoi les antagonistes des autorécepteurs $\left(5-\mathrm{HT}_{1 \Lambda}, 5-\mathrm{HT}_{1 \mathrm{~B}}, 5-\mathrm{HT}_{1 \mathrm{D}}\right)$ constituent une famille de composés d'un grand intérêt potentiel pour le traitement des dépressions (notamment en association avec les inhibiteurs de la recapture de la 5-HT).

Enfin, on peut attendre beaucoup de ligands de tel ou tel récepteur de la 5-HT dans le traitement de désordres comportementaux tels que l'obsession-compulsion, l'anorexie ou au contraire la boulimie, l'agressivité pathologique, etc. Ainsi, des études pharmacologiques ont montré que les récepteurs $5-\mathrm{HT}_{1 \mathrm{~B}}$ et $5-\mathrm{HT}_{1 \mathrm{C}}$ sont impliqués dans l'action anorexigène de la dexfenfluramine - qui libère la 5-HT dans le système nerveux cen- tral. Dès lors, plutôt que d'inonder tous les récepteurs dans la 5-HT ainsi libérée, peut-être vaudrait-il mieux tenter de développer des ligands sélectifs des sous-types $5-\mathrm{HT}_{1 \mathrm{~B}}$ et $5-\mathrm{HT}_{11}$ pour le traitement des troubles de la prise alimentaire?

Or un tel ligand existe déjà ; il s'agit du sumatriptan, dont l'efficacité dans le traitement de la crise de migraine est parfaitement établie. Mais le sumatriptan n'affecte pas la prise alimentaire. En fait, quel que soit le ligand, encore faut-il qu'il pénètre au travers de la barrière hématoencéphalique pour atteindre les récepteurs centraux, ce qui n'est pas le cas du sumatriptan; c'est en stimulant des récepteurs $5-\mathrm{HT}_{1 \mathrm{~B}}$ et $5-\mathrm{HT}_{11)}$ extracérébraux (mais intracrâniens) que ce composé provoque la vasoconstriction de certains vaisseaux dans la dure-mère à l'origine de son action anti-migraineuse [33]. Pour le moment, le récepteur sur lequel agit vraiment le sumatriptan pour exercer son action anti-migraineuse n'est pas connu. Il pourrait s'agir de l'un seulement des sous-types $5 \mathrm{HT}_{1 \mathrm{~B}} /$ $5-\mathrm{HT}_{11}$ que nous avons brièvement décrits. Là encore, l'identification de ce récepteur devrait contribuer au développement de nouveaux médicaments anti-migraineux plus efficaces et entraînant le minimum d'effets secondaires.

Enfin, il convient de rappeler combien sont puissants les antagonistes des récepteurs $5-\mathrm{HT}_{3}$ pour empêcher les nausées et vomissements associés à la chimiothérapie et à la radiothérapie des cancers [33]. Dans ce cas également, les récepteurs concernés semblent être surtout localisés à la périphérie, sur les fibres vagales du complexe gastro-intestinal. Les potentialités des ligands des récepteurs $5-\mathrm{HT}_{3}$ centraux n'en sont pas moins très grandes puisque des effets de types anxiolytique, promnésique, voire antipsychotique ont été décrits chez des animaux traités avec des antagonistes spécifiques des sites $5-\mathrm{HT}_{3}$ [33].

Jusqu'à présent, tous les ligands des différentes classes de récepteurs de la 5-HT, y compris ceux qui sont des médicaments efficaces (sumatriptan, ondansetron, etc.) sont issus de recherches chimiques et pharmacologiques " traditionnelles ". L'apport 
de la biologie moléculaire à la connaissancc fondamentalc de ces récepteurs cst déjà, et sera cncore pour des années, tout à fait spectaculaire. Unc ère nouvellc s'ouvrc actuellement avec la modélisation tridimensionncllc de l'interaction des ligands avec lcurs réceptcurs. C'est ainsi que, dans lc cas du réccpteur $5-\mathrm{HT}_{1 \wedge}$ (figure 3), les acides aminés qui sont très probablement impliqués dans la liaison de la 5-HT sur son sitc de reconnaissance au nivcau des domaines transmembranaircs ont été identifiés, de même que la nature des forces qui régissent cette liaison. Les données de la modélisation montrent en effet que c'est avec la thréonine 200 du $5^{\mathrm{e}}$ domainc transmembranaire qu'interagit l'hydroxyle de la 5-HT, alors que son noyau aromatique réalise une liaison de type hydrophobe avec la phénylalanine 361 du domaine transmembranairc 6 , et que la fonction amine de la $5-\mathrm{HT}$ se lie à la fonction carboxylique de l'aspartatc 116 du $3^{\mathbf{c}}$ domaine transmembranaire [34]. La connaissance de la structurc du réccpteur ct cellc des changements conformationnels qui conduiscnt tantôt à son interaction avec une protéine $G$, tantôt à l'ouverture d'un canal ionique sont aussi des informations dont il conviendra de tenir compte pour la conception optimale de nouveaux ligands. Nous n'en sommes vraiment qu'au premier stade de recherches extrêmement prometteuses pour la mise au point de psychotropes encore plus sélectifs et plus efficaces que ceux dont nous disposons aujourd'hui

TIRÉS A PART

\section{Summary}

Central serotonin receptors

The central neurotransmitter serotonin (5-hydroxytryptamine, $5-\mathrm{HT}$ ) is involved in the control of several brain functions (sleeping/waking cycles, thermoregulation, food consumption, sexual behaviour, nociception, etc.), and alterations in the activity of serotonin-containing neurones have been associated with several neuropsychiatric disorders such as depression, anxiety and dementia. These multiple actions have led to the hypothesis of the existence of several classes of receptors for 5-HT, and pharmacological studies for the last 15 years demonstrated that this is indeed the case. To date, at least 10 distinct receptors for 5-HT have been identified, most of them being cloned and sequenced. Except the receptor called $5-\mathrm{HT}_{3}$, which corresponds to a ligand-gated cation channel, all the 5-HT receptors identified so far belong to the $\mathrm{G}$ protein-coupled superfamily with seven hydrophobic transmembrane domains. Several 5-HT receptor subtypes $\left(5-\mathrm{HT}_{1 \Lambda}\right.$, $5-\mathrm{HT}_{1 \mathrm{~B}}, 5-\mathrm{HT}_{1 \mathrm{D}}, 5-\mathrm{HT}_{1 \mathrm{~B}}$ ) are negatively coupled with adenylase cyclase, whereas only one, the $5-\mathrm{HT}_{4}$, is positively coupled with this enzyme. The other two receptors, the $5-\mathrm{HT}_{1 \mathrm{C}}$ and $5-\mathrm{HT}_{2}$, are positively coupled to phospholipase C. In addition, $G$ proteins activated by these receptors can also influence specific cation $\left(\mathrm{K}^{+}\right.$, $\mathrm{Ca}^{2+}$ ) conductances in target cells of serotoninergic neurones. Extensive studies on the functional properties and cellular location of 5-HT receptors contributed to the present knowledge of the mechanisms of actions of their ligands as potential anxiolytic, antidepressant, anti-migraine or anti-emetic drugs. Computer modelisation of the interaction of 5-HT with these various receptors seems to be a very promising approach for the design of new drugs with additional clinical indications.
La $3^{\circ}$ Conférence internationale sur la Régulation négative de l'héma. topoiêse : des aspects fondamentaux à l'application clinique aura lieu du 18 au 22 avril 1993 à Paris. Elle est organisée par A. Najman, M. Guigon (INSERM), F. Lemoine, F. Isnard, J.-Ph. Laporte ef N.-C. Gorin (CHU Saint-Antoine, Paris) et bénéficie, entre autres, du soutien de I'INSERM.

Comité scientifique international : C. Bréchot (INSERM U.75, F.), H.E. Broxmeyer (USA), J. Caen (F.), N. Dainiak (USA), C. Eaves (Canada), B. Lowenberg (PaysBas), I. Pragnell (G.B.), A. Schechter (USA), P. Tambourin (INSERM/Institut Curie, F.), W. Vainschenker (INSERM U.91, F.), N. Young (USA), D. Zipori (Israël).

\section{Programme :}

Le programme comprendra des séances plénières, des communications orales et affichées sélectionnées sur résumé, suivies de discussions sur les thèmes suivants:

- récepteurs ef leurs inhibiteurs : C. Dinarello (USA), D. Gearing (USA), A. Lodish (USA), J. Pouysségur (F.), F. Ruscetti (USA), J. Samarut (F.), J. Witzerbin (F.) ;

- inhibiteurs du cycle cellulaire : C. Bréchot (F.), M. Dorée (F.), J. Griffin (USA), M. Koury (USA), L. Kretzner (USA), J.-J. Lawrence (F.) ;

- approches moléculaires pour la manipulation des progéniteurs hématopoïétiques : A. Gewirtz (USA), M. Sanders (USA), W. Stratford May (USA) ;

- effets in vitro et in vivo des inhibiteurs de I'hématopoïèse : J. Banchereau (F.), H.E. Broxmeyer (USA), C. Carlo-Stella, (Italie), N. Dainiak (USA), C. Eaves (Canada), M. Guigon (F.), Z. Han (F.), L. Pelus (USA), I. Pragnell (G.B.), P. Quesenberry (USA), P. Ralph (USA), D. Zipori (Israël);

- inhibition de l'hématopoïèse par les cellules leucémiques: M. Freedman (USA), B. Lowenberg (Pays-Bas), A. Najman (F.); - virus et hématopoï̀se par les cellules leucémiques; $M$. Freedman (USA), B. Lowenberg (Pays-Bas), A. Nahman (F.);

- virus et hématopoïoèse : $E$. Gluckman (F.), B. Torok-Storb (USA), N. Young (USA) ; - protection de la moelle au cours de la radio - et chimiothérapie : C. Gorin (F.), M. Guigon (F.), M. Moore (USA), R. Neta (USA), W. Paukovits (Autriche), B. Sredni (Israël), M. Tubiana (F.), J. Zucali (USA).

Les actes de la conférence seront publiés dans la collection des Colloques de I'INSERM, sous forme d'une co-édition INSERM/John Libbey Eurotext.

Date limite de soumission des résumés pour communications orales ou affichées: jer février 1993

Pour tout renseignement complémentaire et inscription, s'adresser a Martine Guigon, Laboratoire d'Hématologie, CHU SaintAntoine, 27, rue Chaligny, 75012 Paris • Télécopie : 40.01.14.99. 